\title{
Destination Image: perception, experience, and behavioural intention: in the context of West Java, Indonesia as a tourist destination
}

\author{
Nono Wibisono \\ Bandung State Polytechnic, \\ Bandung, Indonesia \\ nn_wibisono@yahoo.com
}

\begin{abstract}
Destination image is a critical issue for every tourism destination as it is one of the key influences on the holiday decision-making process. Academic literature on destinationimage draws attention to the problematic concept of 'image' due to its multifaceted meanings and different interpretations. Nonetheless, the received view remains that destination image may be measured and captured using standard instruments. This research develops our understanding of destination image, through the integration of tourist experience and tourist 'accounts' or tales. Building on a mixed method design, the framework is tested using a case study of West Java, Indonesia. This methodology combines a large scale survey, with a number of qualitative semi-structured interviews to provide accounts of experiences. The survey was distributed to both domestic and international tourists (split between visitors and non-visitors) around West Java namely; Bandung, Tangkuban Perahu Crater (West Bandung regency), Botanical Garden (Bogor city), Pangandaran district and beyond the destination, in Jakarta. The findings found that in terms of perception, the average overall score for West Java was 4.75 , which would suggest a weakly positive image, this can be regarded as a below average score (for a 7 point scale), implying that the first key finding is that the image of West Java, whilst positive could be weaker. However, the predominant sense of place amongst visiting tourists was positive; focused on key dimensions of natural beauty, local culture, pleasant environments, relaxation and friendliness. Moreover, significant differences between international and domestic tourists in their image, experience and sense of place is also apparent and suggesting that different segments have different priorities and place narratives. However, significant weaknesses in the image and place narrative were also revealed; suggesting a disjuncture between official destination discourse, tourist perception and experience. A key outcome from this finding shows that the image can be created not only from image component attributes but also from both the sense of place and place experiences. This analysis can provide a framework for destination marketing.
\end{abstract}

Key words : Destination image, perception, experience, behavioral intent, West Java

\section{INTRODUCTION}

The increasing competition among tourist destinations which has taken place in recent years has led to the drive to develop evermore favourable and competitive images of tourist destinations. Destination marketing has been obliged to devote considerable time and energy into improving or maintaining the image of the destination. The literature suggests that in order to establish comparative advantage, a destination needs to create a favourable image by paying attention to improving their tourism products and services, by seeking ways to stand out from competitors, and by creating a positive image in the mind of potential the tourist ([1]; [2]; [3];[4]). Moreover, it is assumed that 'image', therefore, is the most important determinant of the choices made by the tourists ([5], notwithstanding the role of other factors in destination competitiveness ([6]. In general, the 'image' of any destination greatly influences tourist-perception and any resulting change in their behaviour and destination-choice ([7];[8];[9];[10]. Creating a distinctive positive 'image' becomes a fundamental aspect for survival and success within a highly competitive global tourism market.

A great deal of attention has been given to the study of destination-image, but this tends to be dominated by established destinations (see [1]; [7]; [11]; [12]; [13]; [14] ; [15]; [16]; [2]; [5]; [17]; [18]; [19]. On the other hand, in the case of emergent regional destinations in Southeast Asia, like West Java, Indonesia relatively little research exists ([15]); there has not yet been any study of this area. Thus, this research is intended to be a contribution towards researching this area's destinationimage, and also to provide a basis of information from which to create and build a marketing program for West Java in particular as a tourist destination. 


\section{a. West Java}

West Java, with Bandung as it capital city, has a strategic geographic position bordered to the North by the Java Sea and the special region of the capital Jakarta, on the West by Central Java province, to the south by Indian Ocean and the West by the province of Banten. Outside of Jakarta, West Java is the most important economic region in Indonesia with a rapidly growing population. The strength of the local economy together with geographical proximity and relatively easy access from the main urban areas of Central Java and Jakarta, means that domestic tourism is expanding significantly. Moreover, each sub-region has distinctive natural resources including mountains, hills and beaches offering diverse tourism attractions, but also a variety of local culture attractions. However, in terms of image it is trying to emerge from within the shadow of Indonesia and Bali, particularly from an international tourist perspective; and also to establish a growing presence in the mind of domestic visitors. Several West Java tourism experts ([20] supported the view that the image of West Java needed further investigation to developing its identity and to enhance market positioning. Furthermore, these tourism experts also claimed that destination image was crucial to the competitiveness the region needed.

\section{b. The research aims and objectives}

The image of a destination is usually regarded a critical factor for the success of any tourist destination. However, the majority of the research in this area has been conducted from the perspective of the affluent 'Western' tourist visiting 'exotic' or 'other' tourists' places. Accordingly, the understanding of a destinationimage representation has become more complex because of the large spectrum of information sources and channels that exist. Likewise, many information-sources related to West Java's tourism have different starting points and perceptions by the tourists when considering West Java as a tourist destination. Therefore, the objectives of this research are as follows:

- To measure overall image for both domestic as well as international tourists, those who have visited and have never visited

- To test which destination image attributes have a significant impact on behavioural intention for domestic and international tourists, those who have visited and never visited

- To compare how the image changes with actual experience both for domestic and international tourist

\section{LITERATURE REVIEW}

\section{a. Destination Image}

The image of a destination is an interesting topic for tourism marketers, particularly because the research has showed that destination images and tourist purchase decisions positively interact ([21]; [22] ; [8] . Besides, the importance of the concept of tourist destinations has led to a large body of research on the images of particular places ([23]; [1] [15]; [4]. Tourism research about destination image has demonstrated the significant impacts of image on tourist decision making processes ([2] ; [8] ; [24]. Also [13] notes that from a marketer's perspective, destination image relates to decision making and sales of tourist product and services, and also to knowing the target market. Thus, images will play an important role in a visitor's mind before visiting a destination $([25]$.

\section{b. Components of destination image and Destination attributes}

The conceptual framework of destination image developed by [1], focuses on the psychological and functional characteristics of destination image. According to them, a model of destination image can be divided into three continuum attributes. Tangible attributes (functional) are characteristics of an image which are directly observable or measurable, such as price level/costs, transportation infrastructure, types of accommodation which are concerned with the more tangible aspects, and the psychological characteristics, for example, kindliness of staff, safety, place's atmosphere and reputation which are concerned with the more intangible aspects and are more difficult to observe and measure. Secondly, attribute-based on common or unique image. In terms of this, attribute images of the destination can range from perceptions based on 'common' characteristic to those based on 'unique' features or auras. Common attributes are basic features which also appear in many other destinations, like transportation, types of accommodation, price, etc. Unique elements, on the other hand, are special attributes helping a destination to differ from its competitors ([26].

Regarding of destination attributes it is difficult for destination image researchers to find a fixed set of destination attributes because, according to the literature review, there is no single fixed set of destination attributes; rather they are context dependent. Therefore, if the researcher is conducting an inquiry about destination image they are usually using the attractions that a destination has. For example, [12] used attributes 
such as: beautiful scenery/natural attraction, good climate, interesting cultural attractions, suitable accommodation, appealing local food, good value of money, and friendly local residents, in order to compare the image of four Mediterranean countries between visitors and non -visitors. Furthermore, in contributing to understanding of destination attributes [2] classified all attributes into nine dimensions such as Tourist leisure and recreation, Natural resources, general infrastructure, culture, history and art, social environment, tourist infrastructure, political and economic factors, and atmosphere of the place.

\section{METHODOLOGY}

\section{a. Methodology}

\section{Research instrument}

Questionnaire responses can be quantified by assessing numbers of responses according to a given set of rules. Perception of image is fundamentally subjective in nature and, therefore, based on individual respondents. Constructs were measured using Likert-type scales, since this method is simple ([27] and provides a number possible alternative responses to help minimise reliability errors. Moreover, a Likert scale questionnaire survey is the main instrument providing quantitative data, and is designed around opinion statements as a means of exploring respondent perceptions. In terms of measuring destination image perceptions, it is very common to use the Likert scale or semantic differential scale. This research uses a 7-point Likert scale because a 7-point scale is easy for respondents to use and can be applied speedily to a large number of items. In term to measure perception of image this research uses a sevenpoint scale are stated by ' 1 ' (Strongly Disagree), '2' (Disagree), '3' (Disagree Somewhat), '4' (Neutral), '5' (Agree Somewhat), '6' (Agree), and '7' (Strongly Agree). Thus, in order to measure perception of West Java image the researcher developed a questionnaire with 23 attributes based on previous literature on destination image ([1] although the attributes were modified to match the context of this research. Moreover, the reliability and validity of the instrument was evaluated using variety of techniques including content validity and reliability analysis.

\section{b. The sample and data collection}

The sampling frame of this research is the visitors who are visiting or maybe visiting in the future to the destination. The researcher distributed 550 questionnaires divided into 300 questionnaires for domestic and 250 questionnaires for international tourists. For the self-administrated visitor survey, the researcher distributed to the visitors who had visited the destination; yielding a total respondents 350, consisting of 200 domestic and 150 international visitors on site. Menwhile, for the potential visitors from a total respondents 200 consisting of 100 domestic and the rest is international. These questionnaires were distributed in some popular destinations in West Java namely; Bandung, Mount Tangkuban Perahu (West Bandung regency), Botanical garden (Bogor), Pangandaran district and Jakarta. Meanwhile, in terms of semi-structured interviews with a small number of tourists in West Java to capture their impressions and experiences in their own voices. The data collection process took around two and a half months, from in mid June 2012 to the end of August 2012.

\section{c. Data analysis}

Regarding to measure perception of image starts with an examination of overall sample composition, followed by univariate analysis of key independent variables prior to the application of factor attribute and regression analysis. Moreover, in order to measure the tourist behavioural intent a regression analysis was performed. Furthermore. Semi structured inverview were conduct to the repondents who have visited West Java. To analyse the data, this research was used content analysis. This technique was used to identify the most frequent words or phrases used to describe the perception of image from the respondent's voice, and then the data could be divided into component parts/themes.

\section{IV.RESULT AND DISCUSSION}

\section{a. Sample Composition}

The initial analysis focuses on all respondents; those who had visited and those who had not. From A total of 550 usable responses were received showed that in terms of gender, there are slightly more males $(57.6 \%)$ than females (42.4.\%). There appears to be an underrepresentation of older age groups, with sample composition being dominated by productive age groups; $82.7 \%$ were under the age of 45 years. To some extent this is reflected in the educational profile whereby the majority of respondents have tertiary education; $77.2 \%$ are college or university educated. Moreover, approximately $60 \%$ were in professional or managerial occupations in the private sector with a further $15 \%$ composed of civil servants. In terms of domestic 
respondents, the income profile suggests a reasonable spread of income $57.2 \%$ (45 -54 million rupiah) of Indonesian respondents were in above average income brackets. This is consistent with the educational and occupational profile. However, international tourists tend to be more evenly distributed, with $56 \%$ having average or above average salaries (US $\$ 18,000$ - US $\$$ 24,000). Moreover, focusing on the domicile of the survey participants, domestic visitors were more likely to originate from neighbouring areas, such as Jakarta (19.3\%) followed by West Java itself (18.3\%), whilst visitors from Sumatera had almost $17.7 \%$, and the rest were came from different parts of Indonesia. Furthermore, in terms of international visitors the majority could be regarded as Western tourists (69.2\%), with the majority (62\%) coming from Western Europe.

\section{b. Overall tourist perception toward West Java as a tourist destination}

In order to identify the perception of West Java as a tourist destination the respondents were asked to rate various aspects of their perception using a seven-point Likert scale, ranging from 1 (strongly disagree) to 7 (strongly agree). A descriptive analysis was carried out to identify the most important items of tourist perception. Thus, in order to measure tourist perception 23 image attributes of West Java were assessed and summarized using descriptive statistics. Initial analysis suggested that skewness and kurtosis were not a significant problem in the data (see Table 4.1); further visual testing using histograms suggested that the distribution can be taken as normal. Therefore, the mean and standard deviation are appropriate measures and the data is suitable for parametric statistics. The following table shows the mean results for each attribute related to the general perception of West Java as a tourist destination; ranked from the lowest to highest level.

Table 4.1: Perception of West Java as a tourist destination

\begin{tabular}{|c|l|c|c|c|c|}
\hline $\begin{array}{c}\text { Ranki } \\
\mathbf{n g}\end{array}$ & Attributes & Mean & $\begin{array}{c}\text { Standar } \\
\mathbf{d} \\
\text { deviatio } \\
\mathbf{n}\end{array}$ & $\begin{array}{c}\text { Skewnes } \\
\mathbf{s}^{*}\end{array}$ & $\begin{array}{c}\text { Kurto } \\
\mathbf{s i s}\end{array}$ \\
\hline 23 & $\begin{array}{l}\text { Cleanlines } \\
\text { s }\end{array}$ & 4.02 & 1.45 & -.119 & -.527 \\
\hline 22 & $\begin{array}{l}\text { Public } \\
\text { transportati } \\
\text { on }\end{array}$ & 4.41 & 1.39 & -.289 & -.344 \\
\hline 21 & $\begin{array}{l}\text { Infrastruct } \\
\text { ure }\end{array}$ & 4.43 & 1.38 & -.325 & -.323 \\
\hline 20 & TICs & 4.43 & 1.39 & -.171 & -.215 \\
\hline 19 & Museum & 4.59 & 1.38 & -.410 & -.086 \\
\hline 18 & $\begin{array}{l}\text { Entertainm } \\
\text { ent }\end{array}$ & 4.66 & 1.33 & -.288 & -.193 \\
\hline 17 & Cultural & 4.82 & 1.41 & -.451 & -.310 \\
\hline 16 & Adventure & 4.88 & 1.27 & -.439 & -.114 \\
\hline
\end{tabular}

\begin{tabular}{|c|l|c|c|c|c|}
\hline 15 & Historical & 4.95 & 1.43 & -.516 & -.264 \\
\hline 14 & Prices & 4.96 & 1.27 & -.398 & -.247 \\
\hline 13 & $\begin{array}{l}\text { Service } \\
\text { quality }\end{array}$ & 4.96 & 1.19 & -.473 & .105 \\
\hline 12 & Safety & 4.97 & 1.24 & -.577 & .300 \\
\hline 11 & Shopping & 4.98 & 1.33 & -.448 & -.238 \\
\hline 10 & $\begin{array}{l}\text { Accessibili } \\
\text { ty }\end{array}$ & 4.98 & 1.30 & -.571 & .032 \\
\hline 9 & $\begin{array}{l}\text { Accommo } \\
\text { dation } \\
\text { Quality }\end{array}$ & 5.05 & 1.27 & -.469 & -.045 \\
\hline 8 & Recreation & 5.08 & 1.21 & -.636 & .437 \\
\hline 7 & Foods & 5.24 & 1.31 & -.818 & .517 \\
\hline 6 & Value & 5.25 & 1.27 & -.559 & .044 \\
\hline 5 & $\begin{array}{l}\text { Atmosp } \\
\text { here }\end{array}$ & 5.35 & 1.14 & -.756 & .566 \\
\hline 4 & Relaxing & 5.36 & 1.22 & -.799 & .666 \\
\hline 3 & Climate & 5.56 & 1.26 & -1.100 & 1.145 \\
\hline 2 & Scenery & 5.61 & 1.17 & - & 1.705 \\
\hline 1 & $\begin{array}{l}\text { Friendly } \\
\text { people }\end{array}$ & 5.63 & 1.22 & -1.145 & 1.571 \\
\hline & Average & $\mathbf{4 . 7 5}$ & $\mathbf{1 . 3 0}$ & & \\
\hline & & & & \\
\hline
\end{tabular}

From the table above shows the ranking and mean scores of tourist perception as measured using key attributes. Overall the average overall score for West Java was 4.75 , which would suggest a weakly positive image, this can be regarded as a below average score (for a 7 point scale), implying that the first key finding is that the image of West Java, whilst positive could be weaker. The strongest dimensions of West Java's image are 'friendly local people, 'scenery' and 'pleasant climate'. The fact that 'atmosphere', food and 'relaxing' are also highly rated suggests that the sense of place is favourable. Furthermore, attributes like accessibility, shopping, safety, service quality, prices, history, adventure and culture show moderately positive perceptions. However, the remaining of attributes of entertainment, museums, tourism information centre (TICs), infrastructure, public transportation and cleanliness (mean scores between 4.02 - 4.66) represent the weaknesses of the place perception; the attribute with the lowest score was 'cleanliness' (mean score 4.02). This finding is not particularly surprising given that a large number of respondents to the open question on 'negative' perceptions cited cleanliness of toilets, rubbish and poor tourist kiosks.

Furthermore, in order to identify which destination image attribute have a significant impact on on behavioural intention for domestic and international tourists, those who have visited and never visited; Initial hypothesis testing was based on the relationship between overall destination image and recommendation to other visitors. Overall image of the destination was taken as an 
average score for all 23 image attributes. This was tested using a simple bivariate regressionn (see Table 4.2).

Table 4.2: Multiple Regression - Image attributes against recommendation

\begin{tabular}{|c|c|c|}
\hline $\begin{array}{l}\text { Adjusted } R^{2}=0.51 \\
R=0.74\end{array}$ & \multicolumn{2}{|c|}{$F=16.80, p=.000$ Multiple } \\
\hline Variable & Beta & Significance \\
\hline Relaxing & $\beta=.184$ & $\mathrm{p}=.000$ \\
\hline Culture & $\beta=.180$ & $\mathrm{p}=.000$ \\
\hline Value & $\beta=.179$ & $\mathrm{p}=.000$ \\
\hline Safety & $\beta=.158$ & $\mathrm{p}=.002$ \\
\hline Scenery & $\beta=.130$ & $\mathrm{p}=.006$ \\
\hline Atmosphere & $\beta=.124$ & $\mathrm{p}=.000$ \\
\hline Food & $\beta=.115$ & $\mathrm{p}=.023$ \\
\hline Price & $\beta=.103$ & $\mathrm{p}=.030$ \\
\hline Accommodation & $\beta=.-105$ & $\mathrm{p}=.020$ \\
\hline
\end{tabular}

The result indicates that the significant variables that remained in the equation and which influence tourist recommendation based on the standardized Beta coefficients values. The standardized Beta coefficients considered the influence of each independent variable on the dependent variable. Overall the model is successful with a $\mathrm{R}^{2}$ value of 0.51 , suggesting over $50 \%$ of the variance in likelihood of recommending is accounted for by the image attributes. The result suggest that West Java's culture and reputation as a place to relax are the most positive influences on recommendation; along with value for money. On the other hand functional variables (public transport, infrastructure, access, and tourism information centre (TICs) had no impact on likely behaviour. Neither did heritage variables (history, museums) nor those associated with leisure (recreation, and adventure). The negative Beta value for accommodation is an anomaly and may reflect the number of day visitors amongst domestic tourist.

Regarding the perceived importance of destination image items, in general the results indicate that that predominantly tourists tended to weakly hold a moderately positive impression of West Java, and also different group of tourist have a significant differences in their perception. Moreover, destination attributes are linked to intention to visit which also suggests that the perceived of attributes of the destination play an important part in the holiday destination choice for both domestic and international tourists. Those with experience of the destination tended to hold West Java in higher regard and were more positively predisposed in terms of behavioural intent. This finding is in line with the past research conducted by ([2] who noted that tourist visits to a destination are predominantly decided by the image of the destination perceived; based on vacation experience of the destination. Although the relatively weak image is a cause for concern, particularly in the context of international tourism development strategies, it is also an opportunity. The absence of significant negative dimensions does provide the opportunity to begin to craft a 'brand', assuming that the visibility of West Java can be improved. Moreover, as those who had experienced the destination tended to have more positive place perceptions, this implies that the place product is not fundamentally weak. This is not to say that place promotion doesn't need to go hand-inhand with tourism development, as weaknesses in some image attributes do reflected some weaknesses in place product; around infrastructure in particular.

Based on the semi structure interviews using openended questions the results indicate that the respondents who have visited the place, particular themes structure result in the holistic images. In order to determine the categories/codes, all of the respondents' answers or words with similar meaning were placed into categories and grouped (Table 4.3)

Table 4.3: Common themes associated with holistic and unique components of West Java as tourist destination.

\begin{tabular}{|c|c|c|}
\hline Functional/Tangible & Psychological/Intangible & Unique \\
\hline Natural scenic beauty & Relaxing & $\begin{array}{c}\text { Local } \\
\text { culture/Sundanese } \\
\text { authentic food }\end{array}$ \\
\hline Local culture & Friendly people & $\begin{array}{c}\text { Natural scenic } \\
\text { beauty }\end{array}$ \\
\hline Leisure & $\begin{array}{c}\text { Natural environment } \\
\text { (unclean and crowded) }\end{array}$ & Heritage \\
\hline Heritage & & \\
\hline Infrastructure & & \\
\hline
\end{tabular}

According to table 4.3 West Java is perceived as possessing a mixed image associated with natural scenic beauty, local culture (including friendly people and local cuisine), heritage, and relaxing places; as well as infrastructure. This implies that West Java as a destination place is perceived as potentially providing a tangible and intangible tourism package which is supported by tourism infrastructure and facilities; where tourists consider they they get a benefit from visiting the place. Moreover, in terms of holistic image of West Java, this was focused on sense of place - pleasant environment, good food and friendly people. Domestic tourists tend to see West Java as a recreational space, whereas international visitors were more likely to see local culture. In addition, regarding the uniqueness or memorable experiences, these tend to be associated with the qualitative comments with aspects of Sundanese culture, more so with international than domestic visitors. Moreover, in terms of the tourist experience, in 
the context of West Java, natural scenic beauty, and relaxation seems to mean engaging in nature (hot springs for example) or recreational activities. Thus, a number of tourist voices suggest that the nature of scenic beauty, relaxing, and the local people are a key element in place experience and as part of destination image has a significant impact and positive contribution to the destination, and may be more influential towards revisiting and giving recommendations. This is consistent with [10], whereby a favourable destination image perceived through visiting the destination, will produce positive behavioural intentions; such as making recommendation to friends and/or relatives or repeat visitor.

\section{CONCLUSION}

West Java tourism is relatively new emergent phenomena comparing with an established destination in Indonesia such as Bali province, however has developed to the point where it continues to promote by the local government, because this sector has a positive impact to give the economic contribution and social benefits. The findings indicates that in terms of perception, the average overall score for West Java image was weakly positive, thus in order to be sustainable the place need to improve and develop their perception from the tourist point of views. Regarding the tourist experience some image themes emerged from open ending questions. The themes were identified in order to contribute the understanding of destination awareness of the strength and weaknesses of destination image attributes of West Java. According to the themes the result suggest that West Java as a tourist destination associated with natural scenic beauty, local culture, friendly people, pleasant and relaxing places, but lack of infrastructure.

In terms of practical implications, based on the empirical finding, it would be wisely for West Java tourism industry to endeavor and integrate the destination image attributes that transform occurrences into tourist experience. Therefore, in order to enhance and sustain the destination in specific markets, marketing activity needs to comprehend, not only the strength and dimensions of place image, but also incorporate an understanding of how West Java is experienced, or consumed, differentially (by international and domestic visitors) as a tourist place.

\section{References}

Echtner C. M. and Ritchie J. R. Brent, The Measurement of Destination Image: An empirical Assessment, Journal of Travel Research, Vol. 31, pp. 3-13, 1993.

[2] Beerli, A and Martin, C, Factor in influencing destination image. Annals of tourism image research, Vol.31,pp. 657- 681, 2004.

[3] Assaker, G., Vinci, V.E and O'Connor, P, Examining the effect of novelty seeking, satisfaction, and destination image on tourists' return pattern: A two factor, non linier latent growth model. Tourism Management. Vol 32, pp. 890-901, 2011.

[4] Qu, H., Kim, L.S and Im, Holly, H, A model destination branding: Integrating the concepts of the branding and destination image. Tourism Management, Vol, 32, 465476, 2011.

[5] Govers, R. and Go, F, Deconstruction destination image in the trasformation age. Information Technology and Tourism, Vol 6, No1, pp. 13-29, 2003.

[6] Dwyer, L. and C Kim. 'Destination Competitiveness: Determinats and Indicators, Current Issues in Tourism, Vol. 6, No 5, pp. 369-414, 2003.

[7] Fakeye, P.C. and Crompton, J.L. Image differences between prospective, first time, and repeat visitors to the Lower Rio Grande Valley. Journal of Travel Research, Vol.30, No. 10, pp. 10 - 16, 1991.

[8] Bigné, Enrique J., Sánchez, Isabel M. and Sánchez, Javier, Tourism Image, Evaluation Variable and After Purchase Behaviour: Inter-relationship. Tourism Management, Vol.22 No. 6, pp. 607-616, 2001.

[9] Jorgensen, L.G. Unique Singapore. An analysis of a destination image and the language of tourism. The Aarhus Scholl of Business. Available from:http://pure.au.dk/portal/files/2156/000134297134297, 2004.

[10] Lee, C., Lee, Y. and Lee, B., Korea's destination image formed by the 2002 world cup. Annals of Tourism Research, Vo. 32 No.4, pp. 839-858, 2005.

[11] Gartner, W. C. Tourism Development: Principles, Processes and Policies. New York: John Wiley \& Sons Inc, 1996

[12] Baloglu, S. and McCleary, K.W. "US international pleasure travelers' images of four Mediterranean destinations: a comparison of visitors and nonvisitors", Journal of Travel Research, Vol. 38 No. 2, pp. 144-152, 1999.

[13] Jenkins, O.H. Understanding and measuring tourist destination images

[14] Gallarza, M.G., Saura, I.G and Garcia, H.C. Destination Image: Towards Conceptual Framework. Annals of Tourism Research, Vol. 29, No.1, pp. 56-72, 2002.

[15] Pike, Steven. Destination image analysis. A review of 142 papers from 1973-2000 Tourism Management, Vol. 23, No. 5, pp. 541-549, 2002.

[16] Bigne, J. E., Sanchez, I., and Andreau, L., The role of variety seeking in short and long run revisit intention in holiday destinations. International Journal of Culture, Tourism and Hospitality Research, Vol. 3 No. 2 pp. 103115,2009

[17] Tasci, A. D. A., and W.C, Gartner, "Destination image and its functional relationships." Journal of Travel Ressearch, Vol. 45 No .4, pp. 413-425, 2007.

[18] Guthrie, C., and Anderson, A, Visitor narratives: researching and illuminating actual destination experience. Emerald, Qualitative Market Research: An International Journal, Vol.13, No. 2, pp. 110-129, 2010.

[19] Agapito, D., Oom do Valle, P and Mendes, J da Costa, The Cognitive-Affective-Conative Model of Destination. Journal of Travel \& Tourism Marketing. Vol. 30 No. 2, pp. 471-481, 2013.

[20] Interview series with stakeholders. 2013. 
[21] Mayo, E.J and Jarvis, L.P. The Psychology of Leisure Travel. Boston: CBI Publishing, 1981.

[22] Woodside, A.G. and Lysonski, S, “A general model of traveler destination choice", Journal of Travel Research, Vol.7 No. 4, pp, 8-14, 1989.

[23] Mayo, E.J., Regional Images and Regional Travel Behaviour. The Travel Research Association Fourth Annual Conference Proceedings, Sun Valley, Idaho, 1973.

[24] Kim, H and Richardson, S.L, Motion Picture Impacts on Destination Images. Annals of Tourism Research, 30 (1), pp. 216-237, 2003.

[25] McCartney, Glenn, Butlter, Richard, and Bennet, M,. A strategic use the communication mix in the destination image. Journal of Travel Research, 47 (2), pp. 183-198, 2008.

[26] Stepchenkova, S., Russia's Destination Image among American Pleasure Travleers. Master Thesis, Purdue University. Available from:http://plaza.ufl.edu/svetlana.step/research/MSthesis .pdf. 2005.

[27] Finn, M., White, M.E., and Walton, M. Tourism \& Leisure Research Methods, data Collection, Analysis and Interpretation, Essex: Pearson Education, 2000 